\author{
Original Article
}

\title{
Evaluating the Efficacy of a Modified Piezo-Puncture Method on the Rate of Tooth Movement in Orthodontic Patients: A Clinical Study
}

\author{
Maryam Omidkhoda',3 (D), Mehrdad Radvar ${ }^{2,4}$ (ID, Majid Azizi ${ }^{5}$ (D), Mahboobe Dehghani2 ${ }^{2,3}$ (D)
}

\begin{abstract}
'Dental Materials Research Center, Mashhad University of Medical Sciences, Mashhad, Iran
2Dental Research Center, Mashhad University of Medical Sciences, Mashhad, Iran

${ }^{3}$ Department of Orthodontics, Mashhad University of Medical Sciences School of Dentistry, Mashhad, Iran

${ }^{4}$ Department of Periodontics, Mashhad University of Medical Sciences School of Dentistry, Mashhad, Iran

${ }^{5}$ Department of Orthodontics, Birjand University of Medical Sciences School of Dentistry, Birjand, Iran
\end{abstract}

Cite this article as: Omidkhoda M, Radvar M, Azizi M, Dehghani M. Evaluating the Efficacy of a Modified Piezo-Puncture Method on the Rate of Tooth Movement in Orthodontic Patients: A Clinical Study. Turk J Orthod 2020; 33(1): 13-20.

\begin{abstract}
Objective: Owing to the increasing demand from orthodontic patients for a more rapid treatment, many studies have focused on accelerated tooth movement. Currently, one of the prevalent methods to achieve accelerated tooth movement is piezo-puncture. The aim of the present study was to evaluate the effect of a modified piezo-puncture method on tooth movement rate and type during canine retraction.
\end{abstract}

Methods: A total of 17 patients who required fixed orthodontic treatment with extraction of the maxillary first premolars were included in the study. Following a split-mouth design, upper canines were retracted with $\mathrm{Ni}$-Ti coil spring that applied $150 \mathrm{~g}$ of force on each side (piezo-puncture on one side and contralateral side served as the control). Then, the rates of tooth movement, canine angulation and rotation, and anchorage loss were evaluated at T0 (before the intervention), T1 (1 month after the intervention), and T2 (2 months after the intervention). For calculating the canine movement rate, either the distance between the canine and the lateral incisor or the space between the second premolar and the canine was measured. In addition, pain perception was documented by Visual Analog Scale. Data were analyzed using the Kolmogorov-Smirnov normality test, Spearman correlation test, paired sample t-test, and Wilcoxon signed-rank test.

Results: No significant acceleration was observed in canine movement, canine tipping, rotation, or anchorage loss of molar in different times.

Conclusion: Considering the limitations of the study, the application of piezo-puncture employing the protocol used in the present study failed to accelerate tooth movement and to decrease the unfavorable tipping, rotation, and molar anchorage loss.

Keywords: Piezo-puncture, Accelerated tooth movement, Canine retraction

\section{INTRODUCTION}

The duration of orthodontic treatment has always been a critical concern for both patients and clinicians; therefore, many solutions have been proposed in recent years to shorten this period (1). Currently, driven by the growing demand of individuals for faster and shorter orthodontic treatments, many studies tend to focus on accelerated tooth movement (2-11). The first efforts to achieve accelerated tooth movement date back to 1890 (1). One of these early methods was alveolar osteotomy in which the bone cortex and medullary bone were completely separated-primarily involved in the reduction of bone mechanical strength-in an attempt to accelerate tooth movement. In 1959, Köle introduced a procedure involving both osteotomy and corticotomy (3). This new approach involved resecting the cortical bone only, resulting in decreased damage and risks compared with osteotomy. During the years that followed, methods to clinically accelerate tooth movement were attributed to 
reduced bone strength (4). However, in 1983, Frost refuted this concept, arguing that the demineralization and remineralization processes of the alveolar bone are the actual causes responsible for tooth movement acceleration. This phenomenon was termed as regional acceleratory phenomenon (RAP) (5).

Although human and animal studies demonstrated the relative efficacy of corticotomy on the rate of tooth movement, some complications and limitations posed by this method prompted the development of corticision and piezocision (6-11). In contrast to corticotomy, these procedures do not require full-thickness flap reflection, but instead, the use of a small vertical incision through the gingiva fulfills the purpose $(12,13)$. These methods resulted in significantly less trauma and other complications in comparison with the corticotomy method (14).

Some studies have showed that the decortication resulting from piezotome is much more conservative than using a bur and a handpiece. Accordingly, it has been claimed that the vibration of the ultrasonic handpiece could produce a more extensive effect on the osteocytic response (15). Yadav et al. (16) reported no significant increase in tooth movement by applying various low-frequency mechanical vibration, whereas Kalajzic et al. (17) found that tooth movement is significantly inhibited by the application of vibratory forces, and Uribe et al. (18) found that the effect of vibration on accelerating the rate of orthodontic tooth movement is contradictory.

Nevertheless, with the aim of relieving the fear, pain, and discomfort experienced by patients during surgical procedures, a novel method called piezo-puncture was introduced by Kim et al. (19) using an animal model. It is claimed that the piezo-puncture is an optimized less invasive treatment modality, relies on crystallographic, as well as piezoelectric, changes, and involves making several cortical punctures penetrating the gingiva and bone. In this procedure through an ultrasonic tool and sharp tip, without any flap or incision, several punches are created on the gingiva and bone in different locations according to treatment plan and tooth movement direction. Since only one case report is available as clinical study in this subject (20), the aim of this split-mouth clinical trial was to compare the retraction rates of upper canines with sliding mechanics using piezo-puncture method with a control side.

\section{METHODS}

\section{Patient Selection}

This was a clinical controlled trial. The research protocol was reviewed and approved by the ethical committee of the Mashhad University of Medical Sciences (No: 930554, Date: 2015/02/18). A total of 17 ( 7 male and 10 female) healthy subjects were included in the study. Inclusion criteria were minimum age of 14 years and maximum age of 30 years (mean age: 18.23 \pm 1.35 years); maximum anchorage (group A); Class I/crowding or Class II division 1 malocclusion requiring treatment using bilateral extraction of the first premolars and retraction of the maxillary canines with standard full fixed edgewise appliances; presence of a full complement of dentition from first molar to first molar in both arches and possession of a healthy periodontium despite attachment loss of up to $2 \mathrm{~mm}$-yet without any systemic disease; no history of previous orthodontic treatment; no therapeutic intervention, such as maxillary lateral expansion or growth modification treatment; and requirement of at least $3 \mathrm{~mm}$ of canine retraction. Informed consent was obtained from the patients or their legal guardians who agreed to participate in the research.

The orthodontic treatment of patients was scheduled using standard edgewise appliance system with $0.018 \times 0.025$-inch slot (Dentaurum, Germany). Transpalatal arches (TPAs) were inserted in all patients. The right and left maxillary first premolars were extracted approximately 3 months before starting canine retraction. Once leveling and aligning were achieved and before canine retraction, the four incisors were connected using a ligature wire, and accurate alginate impressions were obtained from the upper jaw. Thereafter, a set of study casts were poured in dental stone. Then, the periodontist performed piezo-puncture on the distobuccal, mesiobuccal, mesiolingual, and distolingual sides of the canine (parallel to the long axis of the canine root). Then, $\mathrm{Ni}-\mathrm{Ti}$ coil spring (G\&H, USA) was applied exerting $150 \mathrm{~g}$ of force by connecting to the hook of canines and molars on a 0.016 -inch stainless steel wire for canine retraction. Alginate impression was repeated at the end of the first and second months following spring activation. A code number was allocated to the name of each patient to eliminate possible researcher bias. These code numbers were matched to study casts, and the photographs were obtained from them. A random selection procedure (coin toss) was utilized to consider one side of the participant's upper jaw for piezo-puncture (intervention group) and the other for the control group (no intervention). Further assessment of the photographs, as well as the study casts, was performed 1 month after the completion of the whole project by another researcher who was blind to the intervention group.

\section{Piezo-Puncture Protocol}

Initially, the longitudinal axis and the adjacent teeth roots were evaluated using panoramic radiography. Then, local anesthesia (lidocaine 2\% with epinephrine 1:100,000) was injected into the target area. A piezo-surgery device (24-26 kHz oscillation; Mectron Piezosurgery ${ }^{\circledR}$, Italy) with a curved, sharp head (Sharp Insert Tip, OT6) was used to create the cortical tissue punctures.

The punctures were made $3 \mathrm{~mm}$ deep into the cortical bone by holding the tip of the device perpendicular to the gingiva and bone for $5 \mathrm{~s}$, while normal saline was being dispersed by the machine for cooling in the process (19). Punctures were made starting from 4-5 $\mathrm{mm}$ below the gingival papilla tip. A total of 24 punctures were created in the following order: 8 on the distobuccal side, 8 on the mesiobuccal side (Figure 1. $a, b$ ), 4 on the mesiopalatal side, and 4 on the distopalatal side of the canine teeth along the root axis (Figure 1c). Finally, the patients were advised to use $0.2 \%$ chlorhexidine mouthwash twice a day for 1 week.

\section{Measuring the Rate of Tooth Movement}

The study models were used to measure the amount of canine movement. For this purpose, the following points were identified and marked on the casts: the most distal point on the incisal edge of the lateral incisor, canine cusp tip, distal contact point of the canine, mesial contact point of the maxillary second premo- 

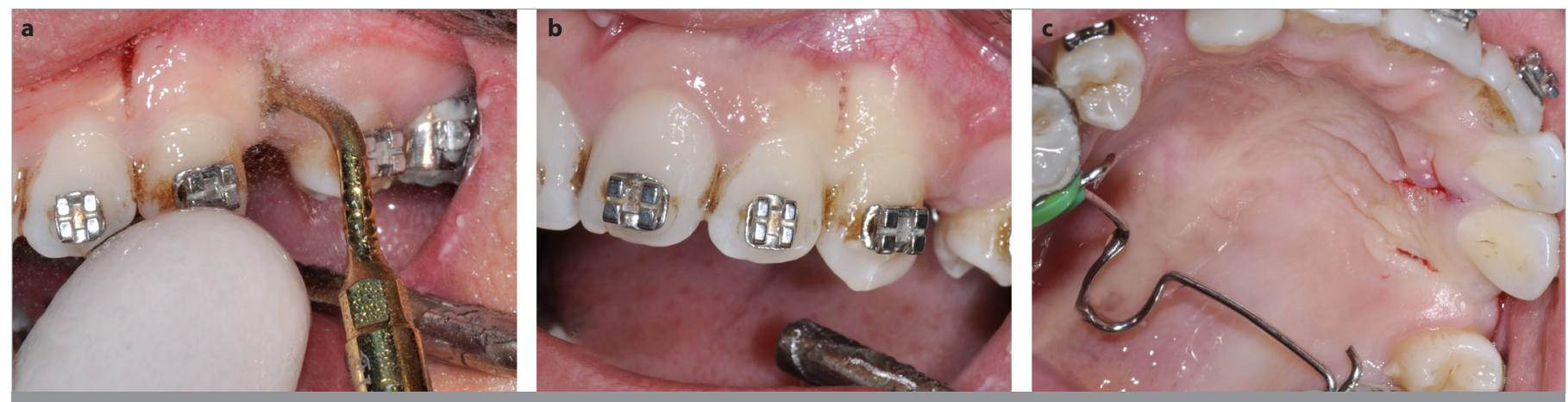

Figure 1. a-c. Punches created in buccal side (a, b) and in palatal side (c)
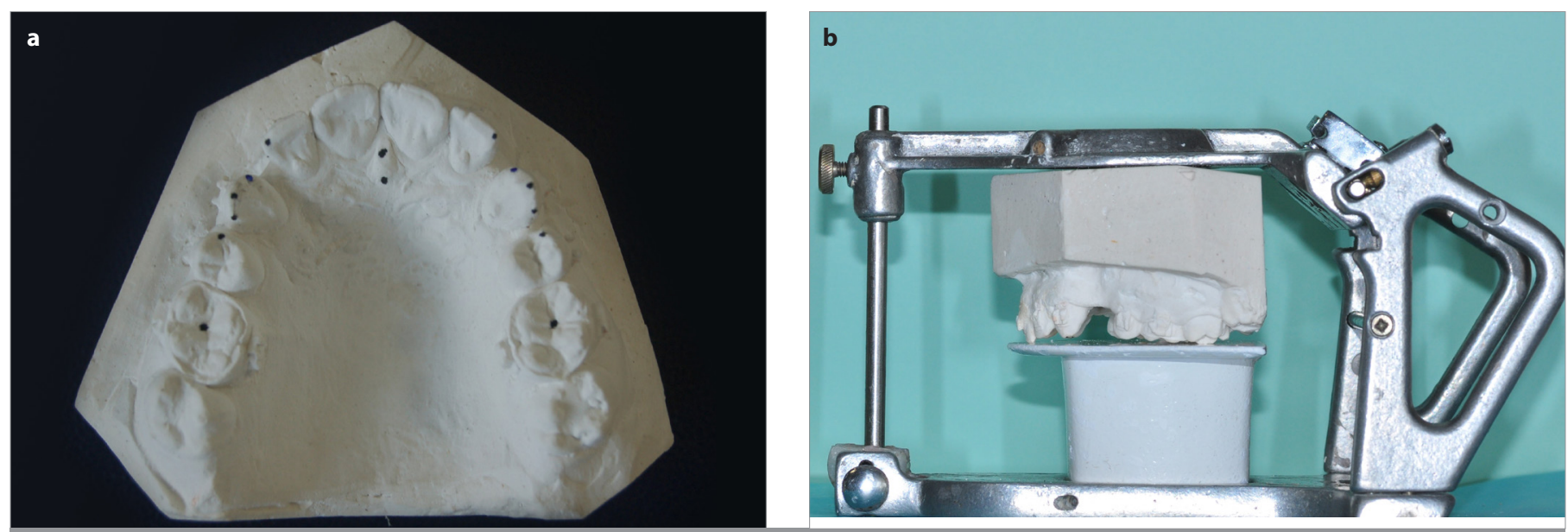

Figure 2. a, b. Identified landmarks on the study model (a), the method of paralleling the occlusal plane with the horizontal plane (b)

lar, central fossa of the maxillary first molar, and the most anterior and posterior points of the incisive papilla (Figure 2a).

Then, the occlusal surface was adjusted using the articulators in the horizontal plane (Figure $2 \mathrm{~b}$ ). The images from all casts were taken with a digital camera positioned at a constant vertical distance from the occlusal surface using the same magnification. Measurements were performed utilizing the Smile Analyzer software (21). Either the distance between the canine cusp tip and the most distal point of the lateral incisor (at incisal level) or the space between the mesial contact point of the second premolar and the distal surface of canine was measured to calculate the tooth movement rate of the canine.

Canine rotation was determined using the angle created between the line connecting the anterior and posterior parts of the incisive papilla (roughly the median palatine suture) and the mesial and distal lines passing through the contact surface of canines during treatment (Figure 3) (22).

A tooth inclination protractor (TIP) device was employed to measure canine tipping during the movement. The metallic wire offered by the TIP device was laid leaning against the labial surface of the canine on the line that passes through the cusp tip and the midpoint of the cervical aspect of the crown. The resultant angle formed between the wires, measured with an angle ruler, was indicative of tooth tipping in the mesiodistal direction (Figure 4) (23).
For the purpose of measuring the amount of molar mesial movement and anchorage loss, an acrylic palatal plug was made on the initial maxillary study model for each patient. Since the acrylic plate of this appliance was almost confined to the rugae area and because this particular site suffered minimal changes in size and shape over time, this appliance could be transferred from the initial cast to the final cast. Acrylic plate included an acrylic part on the palate rugae and the reference wires $(0.019 \times 0.025$-inch stainless steel) that were embedded in this acrylic part, extending to the tip of the canine cusp and the central fossa of the maxillary first molars. After molar movement, the distance between the central fossa and the wire tip was calculated as the amount of mesial molar displacement (Figure 5) (22).

The amount of pain was evaluated using the Visual Analog Scale. After the completion of surgery and the initiation of retraction, the level of pain and discomfort experienced by the subjects during the first and second months following the piezo-puncture surgery was documented by the patients themselves, rating their pain intensity on a scale of $0-10$, where 0 represented no pain and 10 signified severe pain (Figure 6).

\section{Data Analysis and Statistical Analysis}

Data collected from all groups were analyzed by the Statistical Package for Social Sciences for Windows software, version 15.0 (SPSS Inc., Chicago, IL, USA). 

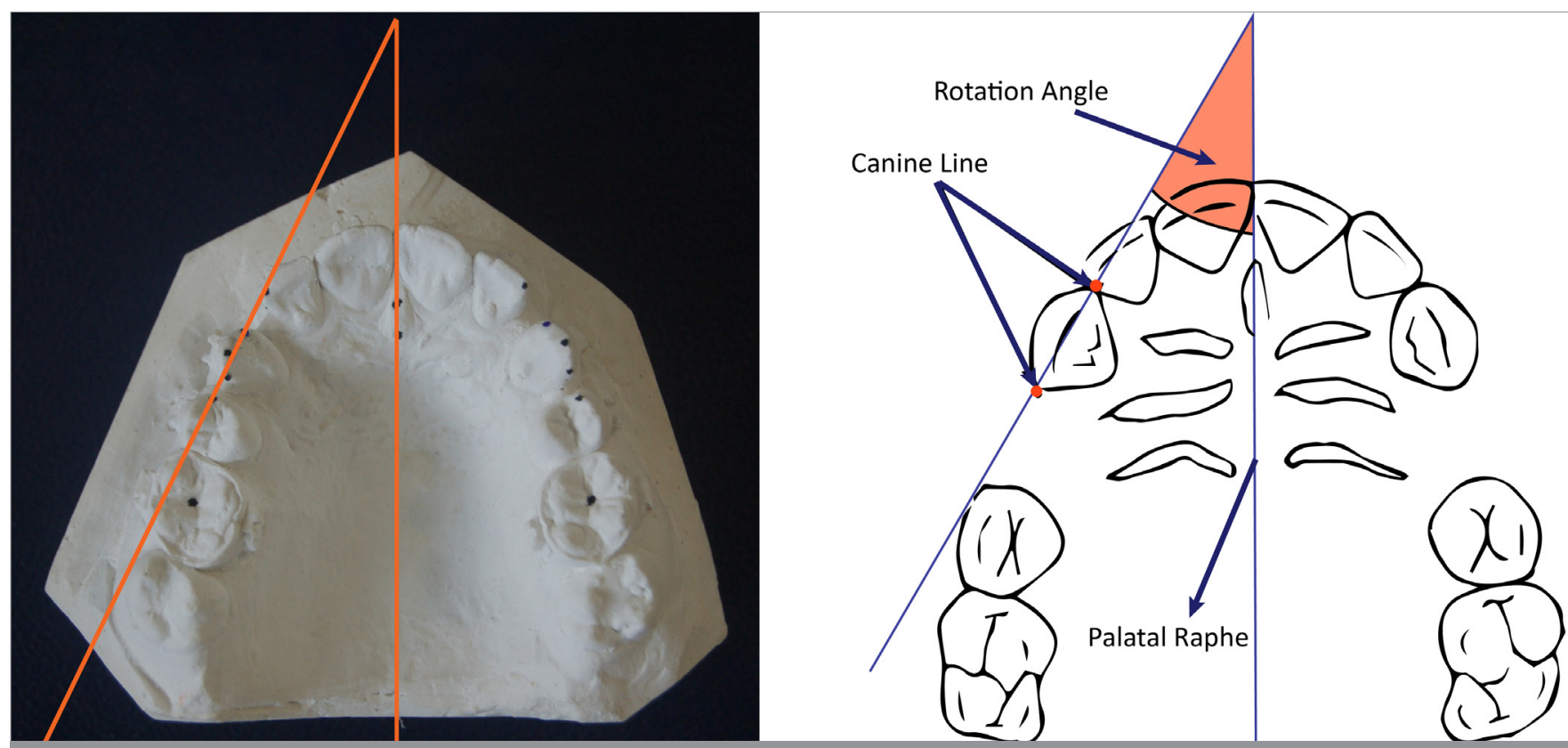

Figure 3. Measurement of canine rotation (22)

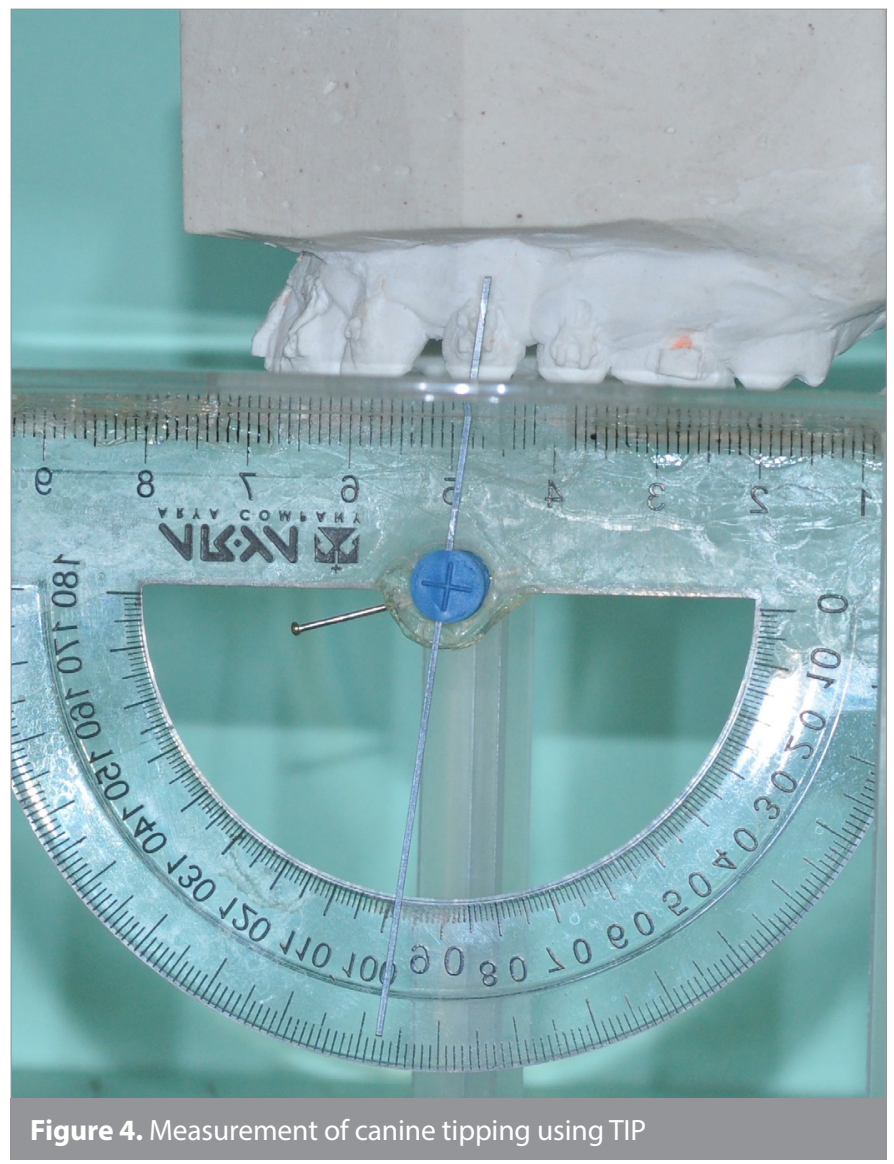

Evaluations were repeated 15 days after the preliminary measurements to assess intraobserver reliability. The second set of values was compared against the initial values using Spearman correlation test. The results showed a significant correlation $(p<0.05)$ between the two sets of measurement values, with the difference being equal to 1 or approximately 1 .

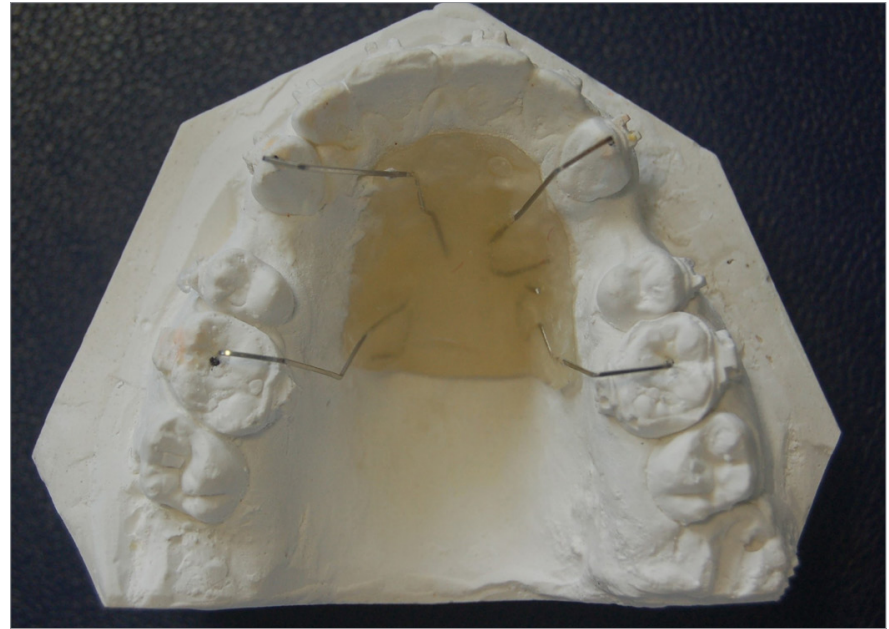

Figure 5. The acrylic plate along with reference wires to measure molar movement rate (anchorage loss)

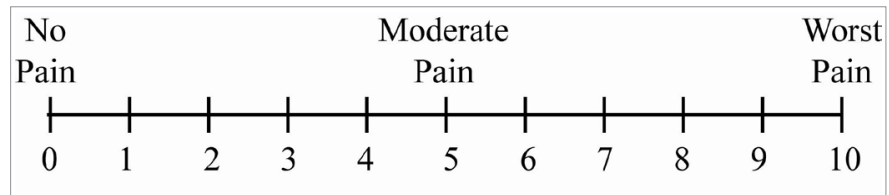

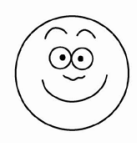

0

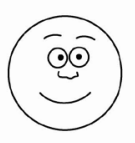

2

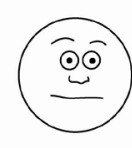

4

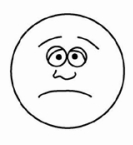

6

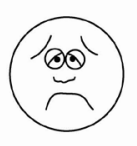

8

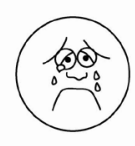

10
Figure 6. The ruler used for measuring the amount of pain

Subsequent to the verification of the reliability of measurements, Kolmogorov-Smirnov normality test was conducted to study the data distribution. The results of this test, for most variables, indicated a data distribution level of 5\%, which was deemed as normal and acceptable. Then, paired sample t-test was utilized 
Table 1. Mean differences, SD, and significance level in the piezo-puncture and control groups

\begin{tabular}{|c|c|c|c|c|}
\hline & Time & Group & Mean $\pm S D^{a}$ & $\mathbf{p}$ \\
\hline Distance between the canine and the & $\mathrm{TO}-\mathrm{T} 1^{\mathrm{b}}$ & Control & $0.74 \pm 0.89$ & 0.169 \\
\hline \multirow[t]{3}{*}{ lateral incisor (mm) } & & Piezo-puncture & $0.88 \pm 1.16$ & \\
\hline & & Piezo-puncture & $0.60 \pm 0.75$ & \\
\hline & $\mathrm{TO}-\mathrm{T} 2^{\mathrm{d}}$ & Control & $0.90 \pm 1.72$ & 0.297 \\
\hline \multirow{4}{*}{$\begin{array}{l}\text { Space between the second premolar } \\
\text { and the canine }(\mathrm{mm})\end{array}$} & & Piezo-puncture & $1.11 \pm 1.92$ & \\
\hline & $\mathrm{T} 1-\mathrm{T} 2$ & Control & $1.17 \pm 1.27$ & 0.53 \\
\hline & & Piezo-puncture & $0.74 \pm 1.15$ & \\
\hline & T0-T2 & Control & $1.62 \pm 3.05$ & 0.93 \\
\hline \multirow{4}{*}{ Canine rotation $\left({ }^{\circ}\right)$} & $\mathrm{T} 1-\mathrm{T} 2$ & Control & $4.24 \pm 3.05$ & 0.58 \\
\hline & & Piezo-puncture & $5.42 \pm 2.17$ & \\
\hline & T0-T2 & Control & $6.87 \pm 6.58$ & 0.54 \\
\hline & & Piezo-puncture & $8.40 \pm 8.11$ & \\
\hline \multirow[t]{5}{*}{ Canine tipping $\left({ }^{\circ}\right)$} & T0-T1 & Control & $3.00 \pm 0.94$ & 0.055 \\
\hline & & Piezo-puncture & $1.60 \pm 0.64$ & \\
\hline & $\mathrm{T} 1-\mathrm{T} 2$ & Control & $1.75 \pm 0.23$ & 0.21 \\
\hline & & Piezo-puncture & $1.53 \pm 0.71$ & \\
\hline & T0-T2 & Control & $2.24 \pm 1.17$ & 0.69 \\
\hline Movement of the first molar (mm) & & Piezo-puncture & $0.35 \pm 0.37$ & \\
\hline \multicolumn{5}{|c|}{$\begin{array}{l}\text { Significance level at } \mathrm{p}<0.05 \text {. } \\
\text { aStandard deviation } \\
\text { 'T0-T1: during the first month of canine retraction } \\
\text { CT1-T2: during the second month of canine retraction } \\
\text { 'T0-T2: total amount of changes during the first and second months }\end{array}$} \\
\hline
\end{tabular}

to analyze the variables related to the amount of canine movement, namely, distal movement, rotation, and anchorage loss, as well as pain.

Considering that the normal distribution of data of tipping values was rejected, Wilcoxon signed-rank test was applied to assess this variable.

\section{RESULTS}

Since the angular and linear measurements were performed at three different time intervals during the study, the relevant tables were summarized as follows for the ease of reading: T0: initiation of treatment, $\mathrm{T} 1$ : the end of the first month, T2: the end of the second month, T0-T1: changes during the first month, T1-T2: changes during the second month, and T0-T2: total amount of changes during the first and second months.

Data regarding the distal movement in the piezo-puncture and control groups at three different time intervals are summarized in Table 1. Based on the achieved data, the movement rate of canines belonging to the piezo-puncture group during the first month, the second month, and after 2 months was not significantly different from that of the control group ( $p>0.05$ ).

The total amount of canine rotation in the piezo-puncture and control groups measured at three different time intervals is summarized in Table 1. According to these mean differences, the rotation of canines on both sides at different times was not significantly different $(p>0.05)$. 


\begin{tabular}{|c|c|c|c|}
\hline Group & Time & Mean difference $\pm S D^{a}$ & $\mathrm{p}$ \\
\hline Control & $\mathrm{TO}^{\mathrm{b}}$ & $0.76 \pm 1.05$ & 0.056 \\
\hline Piezo-puncture & & $1.05 \pm 2.09$ & \\
\hline Control & $\mathrm{T} 0-\mathrm{T} 1^{\mathrm{c}}$ & $0.81 \pm 1.14$ & 0.373 \\
\hline Piezo-puncture & & $0.89 \pm 1.07$ & \\
\hline Control & $\mathrm{T} 1-\mathrm{T} 2^{\mathrm{d}}$ & $0.79 \pm 1.07$ & 0.281 \\
\hline Piezo-puncture & & $0.71 \pm 0.9$ & \\
\hline \multicolumn{4}{|c|}{$\begin{array}{l}\text { Significance level at } p<0.05 \\
\text { aStandard deviation } \\
\text { bAfter piezo-puncture and connection of spring } \\
\text { cDuring the first month of canine retraction } \\
\text { dDuring the second month of canine retraction }\end{array}$} \\
\hline
\end{tabular}

No significant difference was observed in the amount of tipping between the piezo-puncture and on the control sides (Table 1). The tipping values during 2-month of canine retraction were $4.58 \pm 2.39^{\circ}$ on the control side and $5.29 \pm 2.39^{\circ}$ on the piezo-puncture side.

Evaluation of the mesial movement of the first molars revealed that there was no significant difference between the experimental $(0.37 \pm 0.35 \mathrm{~mm})$ and control sides $(0.49 \pm 0.32 \mathrm{~mm})$ in this aspect (Table 1).

The degree of pain experienced at the early stage of treatment (after surgery) was relatively greater on the piezo-puncture side than on the control side, but the difference was not statistically significant $(P>0.05)$. In addition, during the first and second months, no significant pain level was reported by patients in either experimental or control side, and the difference between two sides was not statistically significant (Table 2).

\section{DISCUSSION}

A wide range of surgical intervention methods has been applied on periodontal tissues to accelerate orthodontic tooth movement. The damage caused by such surgical interventions, designed to stimulate the occurrence of the RAP, has been a primary interest factor leading to the development of new surgical techniques that not only accelerate orthodontic tooth movement but also reduce the duration of treatment (24). During the evolutionary process involving techniques, such as osteotomy and corticotomy, followed by corticision, piezocision, and micro-osteoperforation methods in recent years, a more in-depth explanation of the biological and molecular processes has been reported, and researchers are still searching for a more convenient, conservative approach with the hope to further enhance the rate of tooth movement, which can potentially mean the elimination of current problems, reduction of conventional risks, and achievement of comparatively better results (25-28).

One of the latest methods resulting from these attempts is the piezo-puncture method, which involves utilizing a piezoelectric device to create cortical punctures on the attached gingiva around the teeth. It is claimed that this procedure can minimize pain and discomfort in patients-during and after surgery-and increase patient cooperation. On the other hand, since only a few punctures are required, minimal tissue damage is predicted. These pointers regarding the piezo-puncture procedure were presented subsequent to the results of an animal study on beagle dogs. The findings of this study showed rapid tooth movement without any serious damage (19). Following this study, it was deemed necessary to determine the efficacy of the piezo-puncture method in clinical situations. For this reason, the current study employed the piezo-puncture procedure to evaluate the anticipated effect on the movement rate of canines. The study was conducted in the form of a clinical trial following a split-mouth pattern.

Other studies in the literature, which employed more aggressive surgical procedures, such as corticotomy and piezocision, for the purpose of accelerated tooth movement, have reported a faster rate of tooth movement. However, the results of the present study did not indicate any significant increase in the rate of tooth movement. Abbas et al. (29), who used corticotomy and piezocision in their experiment, reported a 1.5- up to 2-fold increase in the rate of canine distal movement. It should be noted that the current study utilized a different method (precisely, a more conservative surgical technique) and therefore, perhaps the reason of the difference between the results of this study with the actual results from other studies employing corticotomy, corticision, piezocision, or micro-osteoperforations due to the proven fact that the rate of the RAP is positively correlated with the severity of the injury (30). However, in relation to studies that have applied piezocision, perhaps the positive impact that these experiments have achieved can be attributed to the depth, length, and number of applied injuries. It is worth mentioning that the method, which was implemented in the course of the present study, involved creating fewer penetrations and perforating a lesser amount of cortical bone than other methods, such as piezocision and corticotomy. The protocol used in the current study applied 16 punctures on the buccal side and 8 punctures on the palatal side. Corticotomy cuts applied in the research performed by Aylikci and Sakin (9) were $10 \mathrm{~mm}$ long and $4 \mathrm{~mm}$ depth. Thus, compared with other studies, the total depth of punch penetration applied to the cortical bone in the present study was decreased (approximately $3 \mathrm{~mm}$ ), which was similar to the results achieved in the study by Kim et al. (19). Several other studies have reported a larger total of puncture depth (up to 4-5 mm) $(10,12,29)$.

The available literature on piezo-puncture method is relatively scant. Therefore, no clinical trial on human population had been conducted to assess the effectiveness of this method. The only source of information available is an animal study by Kim et al. (19) in 2013, which was performed on dogs to evaluate the effectiveness of this particular method on the rate of tooth movement and bone remodeling. Among the possible causes to explain the difference between the results of these two studies, we could point out the different bone structures that humans and dogs possess. In addition, the measurement model applied in the study by Kim et al. (19) was in accordance with the dental and jaw situation of dogs, which is completely different from that of a human study. Anatomical limits of a dog's mouth make 
it completely impossible to install TPAs or springs to ensure generalizability. Moreover, the number of samples examined in that animal study (6 experimental samples and 4 controls) was lower than the present human study (17 samples).

According to the achieved results, although pain perception at the early stages following piezo-puncture was higher on the experimental side than on the control side, the difference was not statistically significant. The pain induced by piezo-puncture might have been clinically negligible. Of course, it should be mentioned that the study followed a split-mouth design, and differentiation between the pain from surgery and that originating from the control sides is difficult, and perhaps, somewhat confusing for the patient.

With respect to the cost/benefit ratio of the piezo-puncture method, it should be mentioned that it is a relatively safe method, inducing the least amount of pain and discomfort for the patient compared with more aggressive surgeries, such as corticotomy. However, the piezo-puncture device should be available in the dental clinic. Although this study did not show significant benefits in favor of the applied method, modifying the protocol of piezo-puncture including the number of punctures or repeating the punctures after a period or measuring the tooth movement in shorter intervals may suggest the clinical efficiency of the piezo-puncture method.

Basically, the intention to cut the soft tissue using the piezo tips will result in crushing or bruising of the tissue rather than cutting. It should be pointed out that in our study, the soft tissue was penetrated by the sharp tips of the piezo blade. The OT6 piezo tip with its saw-shaped design allows the operator to penetrate through the thin soft tissue of the gingiva or oral mucosa with a gentle squeezing of the soft tissue between the points of the tip and bone. Using this technique may cause less soft tissue opening with no need of suturing, although if the soft tissue is thick, the punches may join together, necessitating suturing. We believe that the whole concept of piezo-puncture for tooth movement acceleration is still far from being a standard and universally accepted technique, and therefore a standard and effective piezo-puncture method is yet to be developed.

The authors recommend future studies without split-mouth design to prevent the spreading of the RAP in the entire jaw. In addition, the study period should be considered more than 2 months. Studies with repeated piezo-punctures at regular intervals are recommended to investigate the therapeutic benefits of piezo-puncture procedure in orthodontic tooth movement. Further studies with larger sample size are highly recommended. One of the limitations of the study was using traditional measuring methods rather than digitized or 3D measuring methods. Furthermore, only two time-points were used to measure the amount of space closure per month; RAP is a time-limited process, and therefore the acceleration period might have been missed in this study.

\section{CONCLUSION}

Considering the limitations of this in vivo study and according to the protocol used, it appears that piezo-puncture did not have a significant impact on the canine retraction rate, canine angulation, amount of rotation, and discomfort levels during the first month or at the two examination intervals following surgery compared with the control side.

Ethics Committee Approval: Ethics committee approval was received for this study from the Ethics Committee of the Mashhad University of Medical Sciences (No: 930554, Date: 2015/02/18).

Informed Consent: Informed consent was obtained from the patients or their legal guardians who agreed to participate in the research.

Peer-review: Externally peer-reviewed.

Author Contributions: Supervision - O.M., R.M.; Design - O.M.; Resources - O.M., R.M.; Materials - O.M., R.M.; Data Collection and/or Processing - A.M.; Analysis and/or Interpretation - O.M. A.M.; Literature Search - O.M., A.M., D.M.; Writing Manuscript - O.M., D.M.; Critical Review - O.M., D.M.

Conflict of Interest: The authors have no conflict of interest to declare.

Financial Disclosure: This study was extracted from a postgraduate thesis (no: 600). Hereby, we extend our gratitude to the Research Deputy of Mashhad University of Medical Sciences for their financial support towards this research project.

\section{REFERENCES}

1. Charavet C, Lambert F, Lecloux G, Le Gall M. Accelerated orthodontic treatment using corticotomies: what are the minimally invasive alternatives? Orthod Fr 2019; 90: 5-12. [CrossRef]

2. Davidovitch Z. Tooth movement. Crit Rev Oral Biol Med 1991; 2: 411-50. [CrossRef]

3. Kole H. Surgical operations on the alveolar ridge to correct occlusal abnormalities. Oral Surg Oral Med Oral Pathol 1959; 12: 515-29. [CrossRef]

4. Anholm JM, Crites DA, Hoff R, Rathbun WE. Corticotomy-facilitated orthodontics. Cda J 1986; 14: 7-11.

5. Frost HM. The regional acceleratory phenomenon: a review. Henry Ford Hosp Med J 1983; 31: 3-9.

6. lino S, Sakoda S, Ito G, Nishimori T, Ikeda T, Miyawaki S. Acceleration of orthodontic tooth movement by alveolar corticotomy in the dog. Am J Orthod Dentofacial Orthop 2007; 131: 448.e1-8. [CrossRef]

7. Nimeri G, Kau CH, Abou-Kheir NS, Corona R. Acceleration of tooth movement during orthodontic treatment--a frontier in orthodontics. Prog Orthod 2013; 14: 42. doi: 10.1186/2196-1042-14-42. [CrossRef]

8. Kim SJ, Park YG, Kang SG. Effects of Corticision on paradental remodeling in orthodontic tooth movement. Angle Orthod 2009; 79: 284-91. [CrossRef]

9. Aylikci O, Sakin C. Piezocision-assisted canine distalization. J Orthod Res 2013; 1: 70. DOI: 10.4103/2321-3825.116288. [CrossRef]

10. Brugnami F, Caiazzo A, Dibart S. Lingual orthodontics: accelerated realignment of the "social six" with piezocision. Compend Contin Educ Dent 2013; 34: 608-10.

11. Mittal S, Sharma R, Singla A. Piezocision assisted orthodontics: a new approach to accelerated orthodontic tooth movement. J Innov Dent 2011; 1: 1-4.

12. Dibart $\mathrm{S}$, Keser El. Piezocision ${ }^{\mathrm{TM}}$. Minimally invasive periodontally accelerated orthodontic tooth movement procedure. Orthodontically Driven Corticotomy: Tissue Engineering to Enhance Orthodontic and Multidisciplinary Treatment NJ (USA): editors: Brugnami F, Alfonso C. Wiley-Blackwell 2014: 119. [CrossRef]

13. Dibart S, Sebaoun JD, Surmenian J. Piezocision: a minimally invasive, periodontally accelerated orthodontic tooth movement procedure. Compend Contin Educ Dent 2009; 30: 342-4, 6, 8-50. 
14. Cassetta M, Giansanti M. Accelerating orthodontic tooth movement: A new, minimally-invasive corticotomy technique using a 3D-printed surgical template. Med Oral Patol Oral Cir Bucal 2016; 21: 483-7. [CrossRef]

15. Dibart S, Yee C, Surmenian J, Sebaoun JD, Baloul S, Goguet-Surmenian $\mathrm{E}$, et al. Tissue response during Piezocision-assisted tooth movement: a histological study in rats. Eur J Orthod. 2014; 36: 45764. [CrossRef]

16. Yadav S, Dobie T, Assefnia A, Gupta H, Kalajzic Z, Nanda R. Effect of low-frequency mechanical vibration on orthodontic tooth movement. Am J Orthod Dentofacial Orthop 2015; 148: 440-9. [CrossRef]

17. Kalajzic Z, Peluso EB, Utreja A, Dyment N, Nihara J, Xu M, et al. Effect of cyclical forces on the periodontal ligament and alveolar bone remodeling during orthodontic tooth movement. Angle Orthod 2014; 84: 297-303. [CrossRef]

18. Uribe F, Dutra E, Chandhoke T. Effect of cyclical forces on orthodontic tooth movement, from animals to humans. Orthod Craniofac Res 2017; 20(Suppl 1): 68-71. [CrossRef]

19. Kim YS, Kim SJ, Yoon HJ, Lee PJ, Moon W, Park YG. Effect of piezo-puncture on tooth movement and bone remodeling in dogs. Am J Orthod Dentofacial Orthop 2013; 144: 23-31. [CrossRef]

20. Omidkhoda M, Radvar M, Azizi M, Hasanzadeh N. Piezo-puncture-assisted canine distalization in orthodontic patients: two case reports. J Dent (Shiraz) 2018; 19: 74-82.

21. Rashed R, Heravi F, Raziee L. Smile Analyzer: a software package for analyzing the characteristics of the speech and smile. J Dent Mater Tech 2012; 1: 1-5.
22. Mezomo M, de Lima ES, de Menezes LM, Weissheimer A, Allgayer S. Maxillary canine retraction with self-ligating and conventional brackets. Angle Orthod 2011; 81: 292-7. [CrossRef]

23. Shpack N, Davidovitch M, Sarne O, Panayi N, Vardimon AD. Duration and anchorage management of canine retraction with bodily versus tipping mechanics. Angle Orthod. 2008; 78: 95-100. [CrossRef]

24. Verna C. Regional Acceleratory Phenomenon. Front Oral Biol 2016; 18: 28-35. [CrossRef]

25. Buschang PH, Campbell PM, Ruso S, editors. Accelerating tooth movement with corticotomies: is it possible and desirable? Seminars in Orthodontics 2012: Elsevier. [CrossRef]

26. Alikhani M, Alansari S, Sangsuwon C, Alikhani M, Chou MY, Alyami B, et al. Micro-osteoperforations: Minimally invasive accelerated tooth movement. Semin Orthod 2015; 21: 162-9. [CrossRef]

27. Alikhani M, Raptis M, Zoldan B, Sangsuwon C, Lee YB, Alyami B, et al. Effect of micro-osteoperforations on the rate of tooth movement. Am J of Orthod Dentofacial Orthop 2013; 144: 639-48. [CrossRef]

28. Tsai CY, Yang TK, Hsieh HY, Yang LY. Comparison of the effects of micro-osteoperforation and corticision on the rate of orthodontic tooth movement in rats. Angle Orthod 2016; 86: 558-64. [CrossRef]

29. Abbas NH, Sabet NE, Hassan IT. Evaluation of corticotomy-facilitated orthodontics and piezocision in rapid canine retraction. Am J Orthod Dentofacial Orthop 2016; 149: 473-80. [CrossRef]

30. McBride MD, Campbell PM, Opperman LA, Dechow PC, Buschang $\mathrm{PH}$. How does the amount of surgical insult affect bone around moving teeth? Am J Orthod Dentofacial Orthop. 2014; 145 (Suppl 4): S92-9. [CrossRef] 